\title{
Genetic structure of the threatened Hopea chinensis in the Quang Ninh Province, Vietnam
}

\author{
N.T.P. Trang ${ }^{1}$ and L. Triest ${ }^{2}$ \\ ${ }^{1}$ Department of Molecular Systematics and Conservation Genetics, \\ Institute of Ecology and Biological Resources, \\ Vietnam Academy of Science and Technology, Hanoi, Vietnam \\ ${ }^{2}$ Research Group Plant Biology and Nature Management, \\ Vrije Universiteit Brussel, Brussels, Belgium \\ Corresponding author: N.T.P. Trang \\ E-mail: ntptrang@yahoo.com / ntptrang@iebr.ac.vn \\ Genet. Mol. Res. 15 (2): gmr.15028103 \\ Received November 19, 2015 \\ Accepted January 22, 2016 \\ Published April 29, 2016 \\ DOI http://dx.doi.org/10.4238/gmr.15028103
}

\begin{abstract}
Hopea chinensis Hand-Mazz (synonym H. hongayensis Tardieu), is a wind and insect pollinated species. It is a threatened species known only from two locations: Quang Ninh (Vietnam) and Guangxi (China). As an endemic species, it is worth preserving both for dipterocarp biodiversity, as well as for its medicinal use and economic importance as a fine wood. The genetic diversity and population genetic structure of $H$. chinensis was investigated, using natural populations distributed throughout the Ba Mun and Cai Lim islands, Quang Ninh Province, Vietnam. A total of 65 alleles were detected. The adult allelic richness was higher than that found in juveniles and seedlings in both populations. Inbreeding was found to be significant in Ba Mun adults $\left(F_{\mathrm{ST}}=0.139\right)$, as well as in Cai Lim juveniles and seedlings $\left(F_{\mathrm{ST}}=0.283\right.$ and 0.345 , respectively). Evidence of a bottleneck could be detected in the juveniles and seedlings of the Cai Lim population. A Bayesian analysis and $F_{\mathrm{ST}}$ values suggested high genetic differentiation among the age classes of the Ba Mun and Cai Lim populations. Whereas the adults of the Ba Mun population showed evidence of inbreeding, the
\end{abstract}


next generations showed more potential heterozygotes. In contrast, the adults in the Cai Lim population showed no significant inbreeding, but the observed heterozygosity in the next generation was lower than expected, suggesting significant inbreeding. The $H$. chinensis populations on islands are developed well and showed re-generation under good condition. Thus, the forestry protector should conserve and protect the natural spatial structure of $H$. chinensis on each island as their natural habitats and keep them through natural regeneration.

Key words: Dipterocarp; Genetic conservation; Hopea chinensis; Microsatellites; Population genetics

\section{INTRODUCTION}

Hopea chinensis Hand-Mazz (synonym H. hongayensis Tardieu) naturally distributes only in Guangxi (China) and Quang Ninh (Vietnam). Anumber of studies by Chinese researchers have shown that the bark of $H$. chinensis contains many useful biologically active substances. For instance, Ge et al. (2010) revealed two novel resveratrol aneuploids, hopeachinols A (1) and $B$ (2). In addition, a potent immunosuppressive polyphenol diptoindonesin G (3) was characterized from ethanol extracts of the H. chinensis bark (Ge et al., 2010). Yan et al. (2012) isolated two new polyphenols, hopeachinols C (1) and D (2), in addition to ten known compounds (3-12) (Yan et al., 2012). Compounds 1 and 2 were identified using an extensive analysis of spectroscopic data and computational methods. All of these phytochemicals were tested for acetylcholinesterase inhibitory activity, and five resveratrol-derived compounds (1 and 7-10) exhibited significant activity.

In Vietnam, H. chinensis is only found on the isolated islands at Bai Tu Long National park (Quang Ninh province). The islands in Quang Ninh are on average about 1000 ha in area and isolated from the mainland. Habitat isolation can lead to a reduction in plant population size, which in turn can affect the genetic structure of the populations (Hamrick, 2004) owing to, for example, genetic drift (Ezard and Travis, 2006). However, whether and how the genetic structure is affected by drift depends on the level of gene flow within and among populations (Choo et al., 2012). Thus, potential fragmentation effects strongly depend on a species' mating system, pollen, seed dispersal distance, and effective population size (Kettle et al., 2007). Knowledge of species genetics can inform conservation and restoration initiatives, in order to minimize the extinction risk by maintaining genetic diversity (Kramer et al., 2008). Conservation of species with small and isolated populations is important because these species are expected to lose genetic variation over time resulting in an increased risk of extinction (Ouborg et al., 2006). Small populations also experience an increase in inbreeding, which can result in poor growth, poor seed production, or low seed viability, as a result of inbreeding depression (Oleas et al., 2014).

Microsatellite markers have been used in several dipterocarp tree studies on gene flow, genetic structure, and mating systems (Ujino et al., 1998; Iwata et al., 2000; Takeuchi et al., 2004; Pandey and Geburek, 2009). Several species showed an overall high level of genetic diversity but low overall differentiation, e.g., Dryobalanops aromatica Gaertn. $\left(G_{\mathrm{ST}}=0.067\right.$, Lim et al., $2001)$, Shorea leprosula Miq. $\left(G_{\mathrm{ST}}=0.117\right.$, Lee et al., 2000$)$, and Shorea lumutensis Sym. $\left(G_{\mathrm{ST}}\right.$ $=0.048$, Lee et al., 2004). The objective of the present study was to investigate the details of the 
genetic structure within and between different age classes (adults, juveniles, and seedlings) of $H$. chinensis populations in $\mathrm{Ba}$ Mun and Cai Lim islands. Our aim was to test for potential isolation related effects, local inbreeding, and bottleneck events, using microsatellite markers.

\section{MATERIAL AND METHODS}

\section{Study locations}

A field study was conducted at Ba Mun and Cai Lim islands from August 2012 to October 2013., Both islands belonging to Bai Tu Long National park, Quang Ninh province, Vietnam (Figure 1) Ba Mun Island is a island of about 2000 ha, it stretches nearly $20 \mathrm{~km}$ from north to south and has a maximum altitude of approx. $250 \mathrm{~m}$. The island is characterized by feralit yellowish soils developed on sedimentary rocks with a metamorphic coarse texture. Cai Lim island is composed of half soil half stone and is approximately 1500 ha.

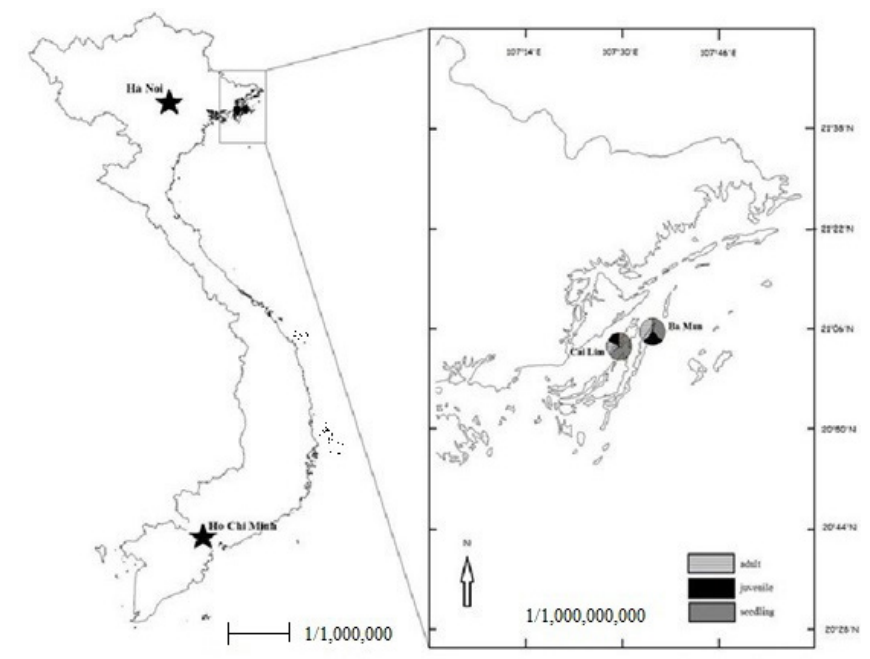

Figure 1. Map of Vietnam with the Hopea chinensis study sites.

\section{Plant materials}

H. chinensis in Ba Mun and Cai Lim islands are big trees, reaching about 20-25 $\mathrm{m}$ in high and $30-35 \mathrm{~cm}$ in diameter. The old bark is grayish brown, splitting into large pieces and leaving circles on the stem. The leaves are simple and alternate. The leaf blades $(10-20 \mathrm{~cm}$ long and 3-7 cm wide) are oblong-ovate, the non-symmetrical base is nearly wedge shaped or rounded, and the apex is acute. The flowers are small with paniculate, axillary inflorescences and include multiple spikes, five sepals, five petals, and ten stamens (Figure 2).

Fruiting appears at more or less regular intervals, typically every two years, with flowering occurring from February to May and fruit maturation occurring between April and July. The fruit consists of a single-seeded nut with a wing-like calyx. Seeds are wind and insect dispersed (Appanah and Chan, 1981). The durable wood of H. chinensis is used for making 
boats, furniture, and bridges. Globally, $H$. chinensis is listed as critically endangered (CR A1cd, B1 + 2c, C1, D) according to the IUCN (1997, 2007, and 2012; http://www.iucnredlist. org/search) criteria. In Vietnam, owing to habitat reduction and over-exploitation, this species is listed as endangered (Vietnam red data book, 2007)
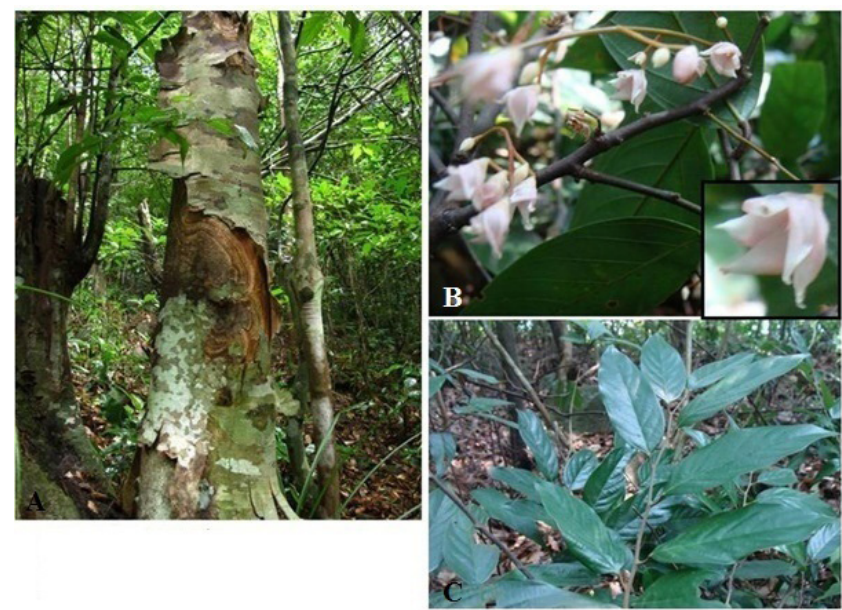

Figure 2. Characteristics of stem (A), flower (B), and leaf (C) of Hopea chinensis in Ba Mun island, Quang Ninh, Vietnam.

In Ba Mun and Cai Lim islands, H. chinensis are clustered in about 1-2 ha in areas with densities of around 100 adult trees per ha. In total, we collected 289 samples (leaf or bark) from the following three age classes based on diameter at breast height (DBH): seedlings $(\mathrm{DBH} \leq 1 \mathrm{~cm})$, juveniles $(1 \mathrm{~cm} \leq \mathrm{DBH} \leq 5 \mathrm{~cm})$, and adults $(\mathrm{DBH}>5 \mathrm{~cm})$ (Table 1). The samples were immediately placed in paper envelopes and plastic bags with silica gel, and then transferred to the Laboratory of Molecular Systematic and Conservation Genetics, Institute of Ecology and Biological Resources, Vietnam Academy of Science and Technology. There, they were stored at $-86^{\circ} \mathrm{C}$ until DNA extraction. Voucher specimens were stored at the Botany department, Institute of Ecology and Biological Resources.

Table 1 - Location and number samples of each age class tree from two populations (Ba Mun: BM and Cai Lim: CL) of Hopea chinensis collected in the Quang Ninh province.

\begin{tabular}{|c|c|c|c|c|c|}
\hline Population & Sample age & Sample size & Altitude (m) & Latitude & Longitude \\
\hline \multirow[t]{3}{*}{$\mathrm{BM}$} & Adults & 34 & \multirow[t]{3}{*}{230} & \multirow[t]{3}{*}{$21^{\circ} 03^{\prime} \mathrm{N}$} & \multirow[t]{3}{*}{$107^{\circ} 35^{\prime} \mathrm{E}$} \\
\hline & Juveniles & 31 & & & \\
\hline & Seedlings & 33 & & & \\
\hline \multirow[t]{3}{*}{ CL } & Adults & 35 & \multirow[t]{3}{*}{130} & \multirow[t]{3}{*}{$21^{\circ} 03^{\prime} \mathrm{N}$} & \multirow[t]{3}{*}{$107^{\circ} 30^{\prime} \mathrm{E}$} \\
\hline & Juveniles & 36 & & & \\
\hline & Seedlings & 120 & & & \\
\hline
\end{tabular}

\section{DNA extraction}

Total DNA was extracted from the samples using the modified CTAB method proposed by Doyle and Doyle (1987). Liquid nitrogen was added to about $100 \mathrm{mg}$ of each sample, which 
was then ground by hand. Total DNA yield and purity were assessed by spectrophotometer and visualized on $1 \%$ agarose gel. Stock DNA was diluted to a concentration of $10 \mathrm{ng} / \mu \mathrm{L}$.

\section{SSR-PCR-Amplification}

Fifteen SSR primers of the related species Shorea curtisii Dyer ex King (Ujino et al., 1998) and Neobalanocarpus heimii (King) Ashton (Iwata et al., 2000) were initially tested for cross amplification in twelve samples from each of the $H$. chinensis populations. Based on their amplification, ten primers that gave polymorphic PCR products were selected for the examination of the whole sample set (Table 2). Polymerase chain reaction (PCR) was performed in a $25 \mu \mathrm{L}$ reaction mixture containing $5 \mu \mathrm{L}$ total DNA (equivalent to $50 \mathrm{ng}$ DNA), $2.5 \mu \mathrm{L} 10 \mathrm{X}$ PCR buffer, $200 \mathrm{nM}$ of each primer, $1 \mathrm{U}$ Taq DNA polymerase (Omega- Omega Bio-tek, 400 Pinnacle Way, Ste 450 Norcross, GA 30071), $2.5 \mathrm{mM} \mathrm{MgCl}$, and $0.2 \mathrm{mM}$ of each dNTP. The PCR reactions were performed in a thermal cycler (MyCycler- www.Bio-Rad.com), using the following conditions: 1 cycle at $95^{\circ} \mathrm{C}$ for $5 \mathrm{~min}$, followed by 35 cycles at $95^{\circ} \mathrm{C}$ for $1 \mathrm{~min}, 45^{\circ} \mathrm{C}$ for $1 \mathrm{~min}, 72^{\circ} \mathrm{C}$ for $1 \mathrm{~min}$, and a final extension at $72^{\circ} \mathrm{C}$ for $5 \mathrm{~min}$. The PCR products were separated by capillary electrophoresis on a QIAxcel system (Qiagen, Hilden, Germany). The genotyping of the microsatellite fragments was conducted on ABI 3500 (Macrogen, Korea, dna. macrogen.com). The fragment size was determined based on the size standard GS-600, using GeneMarker v. 1.91, and manually checked for consistency and accuracy.

Table 2. Microsatellite features with SSR loci, repeat motif, primer sequences, size and number of alleles per locus in Hopea chinensis.

\begin{tabular}{|c|c|c|c|c|c|}
\hline \multirow[t]{2}{*}{ SSR locus } & \multirow[t]{2}{*}{ Repeat motif } & \multirow[t]{2}{*}{ Primers sequences } & \multirow[t]{2}{*}{ Size (bp) } & \multicolumn{2}{|c|}{ Allele number } \\
\hline & & & & Ba Mun & Cai Lim \\
\hline Shc9 & $(\mathrm{CT})_{12}$ & $\begin{array}{l}\text { F:TTTCTGTATCCGTGTGTTG } \\
\text { R:GCGATTAAGCGGACCTCAG }\end{array}$ & $235-335$ & 8 & 6 \\
\hline Shc2 & $(\mathrm{CT})_{2} \mathrm{CA}(\mathrm{CT})_{5}$ & $\begin{array}{l}\text { F:CACGCTTTCCCAATCTG } \\
\text { R:TCAAGAGCAGAATCCAG }\end{array}$ & $135-145$ & 3 & 3 \\
\hline Shc3 & $(\mathrm{CT})_{8}$ & $\begin{array}{l}\text { F:TTGAAGGGAAGGCTATG } \\
\text { R:CTTCTCAACTACCTTACC }\end{array}$ & $115-125$ & 3 & 3 \\
\hline Shc17 & $(\mathrm{CT})_{5} \mathrm{AT}(\mathrm{CT})_{4}$ & $\begin{array}{l}\text { F:CTAGAATCCGCCATTTCC } \\
\text { R:CACAAATACGTCTCCATATC }\end{array}$ & $100-111$ & 1 & 1 \\
\hline Shc11 & $(\mathrm{CT})_{4} \mathrm{TT}(\mathrm{CT})_{5}$ & $\begin{array}{l}\text { F:ATCTGTTCTTCTACAAGCC } \\
\text { R:TTAGAACTTGAGTCAGATAC }\end{array}$ & $112-120$ & 2 & 2 \\
\hline Shcl & $\begin{array}{l}(\mathrm{CT})_{8}(\mathrm{CA})_{10} \mathrm{CT} \\
(\mathrm{CA})_{4} \mathrm{CTA}\end{array}$ & $\begin{array}{l}\text { F:GCTATTGGCAAGGATGTTCA } \\
\text { R:CTTATGAGATCAATTTGACAG }\end{array}$ & $130-144$ & 3 & 3 \\
\hline Nhe5 & $(\mathrm{CT})_{14}$ & $\begin{array}{l}\text { F:GGAGGTGTAAACAAACTCAGTG } \\
\text { R:CTACATAATTGTGCAAACTAGGC }\end{array}$ & $113-129$ & 3 & 3 \\
\hline Nhe19 & $(\mathrm{GA})_{14}$ & $\begin{array}{l}\text { F:ATCAGAGTAGCCATGTTGCTTG } \\
\text { R:GGAGAGACTGGGCTTGCTC }\end{array}$ & $198-350$ & 4 & 4 \\
\hline Nhe11 & $(\mathrm{GA})_{19}$ & $\begin{array}{l}\text { F:CCATCTGAGGGTGTTGAAAG } \\
\text { R:GAGTAGAAGAAGGCAGGTGATTA }\end{array}$ & $144-272$ & 4 & 4 \\
\hline Nhe4 & $(\mathrm{GA})_{19}$ & $\begin{array}{l}\text { F:ACGCAAGCCAACACATCC } \\
\text { R:TTTGCCATTTCACAATCATCAC }\end{array}$ & $214-370$ & 3 & 2 \\
\hline
\end{tabular}

\section{Data analyses}

A suite of genetic parameters was calculated using GenAlex (Peakall and Smouse, 2006) and FSTAT (Goudet, 1995). These included the mean number of alleles $\left(N_{\mathrm{A}}\right)$, allelic richness $\left(N_{\mathrm{AR}}\right)$ per age class, observed $\left(H_{\mathrm{O}}\right)$ and expected $\left(H_{\mathrm{E}}\right)$ heterozygosity, the coefficient of excesses of homozygotes or heterozygotes compared with panmictic expectations within 
age classes ( $F_{\mathrm{IS}}, 1000$ permutations), and the genetic differentiation $\left(F_{\mathrm{ST}}, 1000\right.$ permutations) between age classes. F-statistics were determined following Weir and Cockerham (1984), as used in FSTAT with a Jackknifing procedure applied across loci to derive the significance level. These population structure parameters are defined as the correlations between pairs of genes within individuals $(\mathrm{Cap} F)$, between individuals in the same age class $(\theta$, theta), and within individuals within age class (smallf). These are analogous to Wright's $F_{\mathrm{IT}}, F_{\mathrm{ST}}$, and $F_{\mathrm{IS}}$, respectively. Each locus was checked for evidence of null alleles, scoring errors, and allele drop out, using MICRO-CHECKER (Van Oosterhout et al., 2004).

We tested for recent bottlenecks in each age class and each population under the twophase model (TPM) with 70\% single-step mutations and 30\% multiple-step mutations using BOTTLENECK v. 1.2.02 (Piry et al., 1999). To determine the population "genetic reduction signatures", the characteristics of recent reductions in effective population size, Wilcoxon's heterozygosity excess test (Piry et al., 1999), standard differential test, sign test, and allele frequency distribution mode shift analysis (Luikart et al., 1998) were performed. Exact tests of deviation from the Hardy-Weinberg equilibrium for all loci and among populations were performed at the significance level $(\mathrm{P}<0.05)$. Significance testing for variance components in the analysis of molecular variance (AMOVA) was implemented on the basis of 1000 permutations. Pairwise $F_{\mathrm{ST}}$-values, based on $\theta$, were calculated between all age class pairs and populations, as well as tested for significant differentiation using 999 permutations.

A Bayesian clustering method (Pritchard et al., 2000) was carried out using STRUCTURE v. 2.3.4 (Evanno et al., 2005). The number of differentiated genetic

clusters $(\mathrm{K})$ from 1 to 5 was tested in ten independent runs (10,000 burn-in and 50,000 Markov chain Monte Carlo replicates in each run), without using sampling location as a prior to assess convergence of $\ln (\mathrm{PD})$ (Plot of mean posterior probability values). The runs were carried out assuming admixture and an independent model of allele frequencies. The results were uploaded into STRUCTURE HARVESTER (Earl and vonHoldt, 2011), which estimates the most likely $\mathrm{K}$ value. The number of clusters was determined from the $\mathrm{K}$ with the highest posterior probability and using the second-order rate of change of the likelihood function $\Delta \mathrm{K}$, as suggested by Evanno et al. (2005). A principal coordinates analysis (PCoA) was conducted in GenAlex v. 6.5, to summarize pairwise $F_{\mathrm{ST}}$ values.

\section{RESULTS}

\section{Genetic variation}

The ten SSR loci produced a total of 65 different alleles ranging in size from 100 to $370 \mathrm{bp}$, across all 289 trees of two populations of $H$. chinensis species. Nine SSR loci produced 31 alleles in the Cai Lim (CL) population and 34 alleles in the Ba Mun (BM) population (Table 2). The proportion of polymorphic loci was high (approx. 90\%) in both populations. The $N_{\mathrm{AR}}$ was 3.0 in the adult age class and 2.6 in both the juvenile and seedling age classes of the BM population. In the CL population, $N_{\mathrm{AR}}$ was 3.1, 2.6, and 3.0 in the adult, juvenile, and seedling classes, respectively. Similarly, the frequency of observed heterozygosity $\left(H_{\mathrm{O}}\right)$ ranged from 0.261 to 0.381 and from 0.283 to 0.420 in the BM and CL populations, respectively. Both BM and CL populations showed moderate levels of genetic diversities $\left(H_{\mathrm{O}}\right.$ and $\left.H_{\mathrm{E}}<0.5\right)$ in all three age classes (Table 3). 
Table 3. Genetic variation within populations at ten microsatellite loci.

\begin{tabular}{|c|c|c|c|c|c|c|c|}
\hline Population & $N$ & $N_{\mathrm{A}}$ & $N_{\mathrm{AR}}$ & $\mathrm{P}$ & $H_{\mathrm{O}}$ & $H_{\mathrm{E}}$ & $F_{\text {IS }}$ \\
\hline \multicolumn{8}{|c|}{ Hopea chinensis in Ba Mun island } \\
\hline Adults & 34 & 3.0 & 3.0 & 90 & 0.382 & 0.437 & $0.139 *$ \\
\hline Juveniles & 31 & 2.6 & 2.6 & 90 & 0.261 & 0.310 & $0.172 *$ \\
\hline Seedlings & 33 & 2.6 & 2.6 & 80 & 0.330 & 0.367 & 0.116 \\
\hline Mean & & 2.7 & 2.7 & 86.67 & $\begin{array}{c}0.325 \\
(0.056 \mathrm{SE})\end{array}$ & $\begin{array}{c}0.371 \\
(0.044 \mathrm{SE})\end{array}$ & $\begin{array}{c}0.137 \\
(0.076 \mathrm{SE})\end{array}$ \\
\hline \multicolumn{8}{|c|}{ H. chinensis in Cai Lim island } \\
\hline Adults & 35 & 3.1 & 3.1 & 90 & 0.420 & 0.453 & 0.087 \\
\hline Juveniles & 36 & 2.6 & 2.6 & 90 & 0.286 & 0.392 & $0.283^{*}$ \\
\hline Seedlings & 120 & 3.1 & 3.0 & 90 & 0.283 & 0.430 & $0.345^{*}$ \\
\hline Mean & & 2.9 & 2.9 & 90 & $\begin{array}{c}0.330 \\
(0.044 \mathrm{SE})\end{array}$ & $\begin{array}{c}0.425 \\
(0.041 \mathrm{SE})\end{array}$ & $\begin{array}{c}0.283 \\
(0.091 \mathrm{SE})\end{array}$ \\
\hline
\end{tabular}

$N$, population size; $N_{\mathrm{A}}$, mean number of alleles per locus; $N_{\mathrm{AR}}$, mean number of alleles richness; $\mathrm{P}$, the percentage of polymorphic loci; $H_{\mathrm{O}}$ and $H_{\mathrm{E}}$, mean observed and expected heterozygosity, respectively; $F_{\mathrm{IS}}$, Wright's inbreeding coefficient. Asterisks denote significance at the levels $\mathrm{P} \leq 0.05\left(^{*}\right), \mathrm{P} \leq 0.01(* *)$, and $\mathrm{P} \leq 0.001$ (***).

All age classes of both the BM and CL populations (with the exception of the adult age class of CL) showed positive inbreeding values $\left(F_{\text {IS }}>0.1\right)$, indicating an excess of homozygotes and potential inbreeding. The positive $F_{\text {IS }}$ values indicate a lack of heterozygotes through either inbreeding or the presence of null alleles. Null alleles are commonly found when microsatellite loci are cross-amplified among distantly related species or genera. The MICRO-CHECKER results indicated that null alleles might be present at locus Nhe11. This locus was verified for the presence of various heterozygotes and their inbreeding coefficient $\left(F_{\text {IS }}\right)$, using FSTAT. While heterozygotes were present, the observed heterozygosity was always lower than expected. This lends evidence to inbreeding, rather than null alleles, in these populations. Significant inbreeding was observed for the BM adult and juveniles age class and for the CL juvenile and seedling age classes with $F_{\text {Is }}$-values of $0.139,0.1720 .283$, and 0.345 , respectively.

According to the data for the heterozygosity excess examined using the TPM, we found evidence of recent population reductions or bottlenecks for the CL seedling age class $(\mathrm{TPM}=0.023)$. The CL juvenile age class, although no significant evidence for a bottleneck was found, showed a very low TPM (0.086). The three BM age classes and the adult age class of CL showed no evidence of a recent bottleneck.

\section{Genetic structure}

The AMOVA revealed a high within-population variation ( 81 and $92 \%$ for the BM and CL populations, respectively). The $F_{\mathrm{ST}}$ was 0.195 and 0.081 for BM and CL, respectively, whereas the $F_{\mathrm{IT}}$ for BM was 0.279 and for $0.284 \mathrm{CL}$. The $F_{\text {IS }}$ value was 0.175 in BM and 0.284 in $\mathrm{CL}$ and both of them none significant. The overall estimation of $\mathrm{Cap} F, \theta$, and Small $f$ showed results similar to those obtained from the AMOVA (Table 4).

The largest differentiation (0.256) was found between adult and juvenile age classes of BM population and the lowest (0.0513) between the juvenile and seedling age classes of CL. The pairwise $F_{\mathrm{ST}}$ values of each age classes were significant (Table 5) and ranged from 0.117 to 0.256 for the BM population and 0.513 to 0.106 for the CL population. The Bayesian assignment of individuals with STRUCTURE showed that the three BM age classes were not mixed (Figure 3). 
Table 4. Estimation of $\mathrm{Cap} F$, Theta $(\theta)$ and Smallf (Weir \& Cockerham (1984) in two populations of Hopea chinensis species.

\begin{tabular}{l|c|c|c}
\hline Population & Cap $F$ & $\theta$ & Small $f$ \\
\hline BM & 0.307 & 0.197 & 0.137 \\
\hline CL & 0.338 & 0.079 & 0.283 \\
\hline
\end{tabular}

Table 5. Age class tree pairwise $F_{\mathrm{ST}}$ and significant values.

\begin{tabular}{|c|c|c|c|}
\hline & Adults & Juveniles & Seedlings \\
\hline \multicolumn{4}{|c|}{ H. chinensis in Ba Mun island } \\
\hline Adults & - & $* *$ & $* *$ \\
\hline Juveniles & 0.2560 & - & $* *$ \\
\hline Seedlings & 0.1863 & 0.1170 & - \\
\hline \multicolumn{4}{|c|}{ H. chinensis in Cai Lim island } \\
\hline Adults & - & $* *$ & $* *$ \\
\hline Juveniles & 0.1057 & - & $* *$ \\
\hline Seedlings & 0.0513 & 0.0953 & - \\
\hline
\end{tabular}

Asterisks denote significance at the levels $\mathrm{P} \leq 0.05(*), \mathrm{P} \leq 0.01(* *)$, and $\mathrm{P} \leq 0.001(* * *)$."
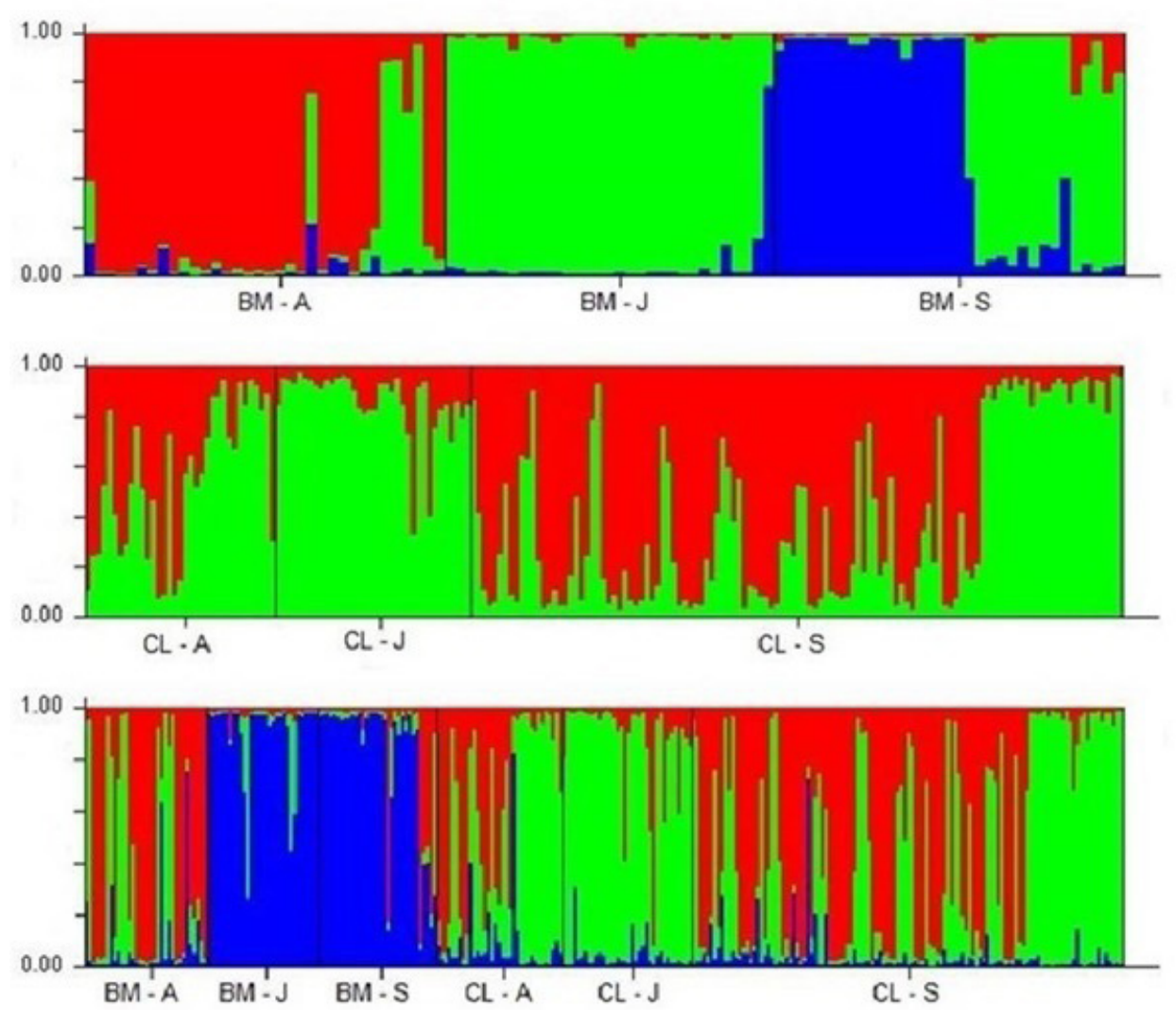

Figure 3. Structure analysis of the three age classes (A: adult, J: juvenile, and S: seedling) for the two Hopea chinensis populations (BM: Ba Mun, top panel; and CL: Cai Lim, middle panel). The bottom panel shows the combined results. 
We obtained three genetic clusters for $\mathrm{BM}$ with the highest $\ln (\mathrm{PD})$ values for $\mathrm{K}=3$ and $\Delta \mathrm{K}=110.65$. In the CL population, two genetic clusters were obtained with the highest $\ln (\mathrm{PD})$ obtained at $\mathrm{K}=2$. The $\Delta \mathrm{K}$ value was 59,291 but varied among the age classes. The combination of the two populations also showed three genetic clusters $(\Delta \mathrm{K}=105.58)$ in which the juvenile and seedling age classes of BM were different from the adult age class and all three CL age classes.

A PCoA was used to examine the population structure as distributed throughout the entire genome. The three age classes in the BM population were divided into three clear groups, with the first and second principal coordinates accounting for 32.82 and $21.14 \%$, respectively. In contrast, the three age classes in the CL population were divided into two groups, based on the PCoA. The first and the second principal coordinates accounted for 26.65 and $21.42 \%$, respectively (Figure 4).
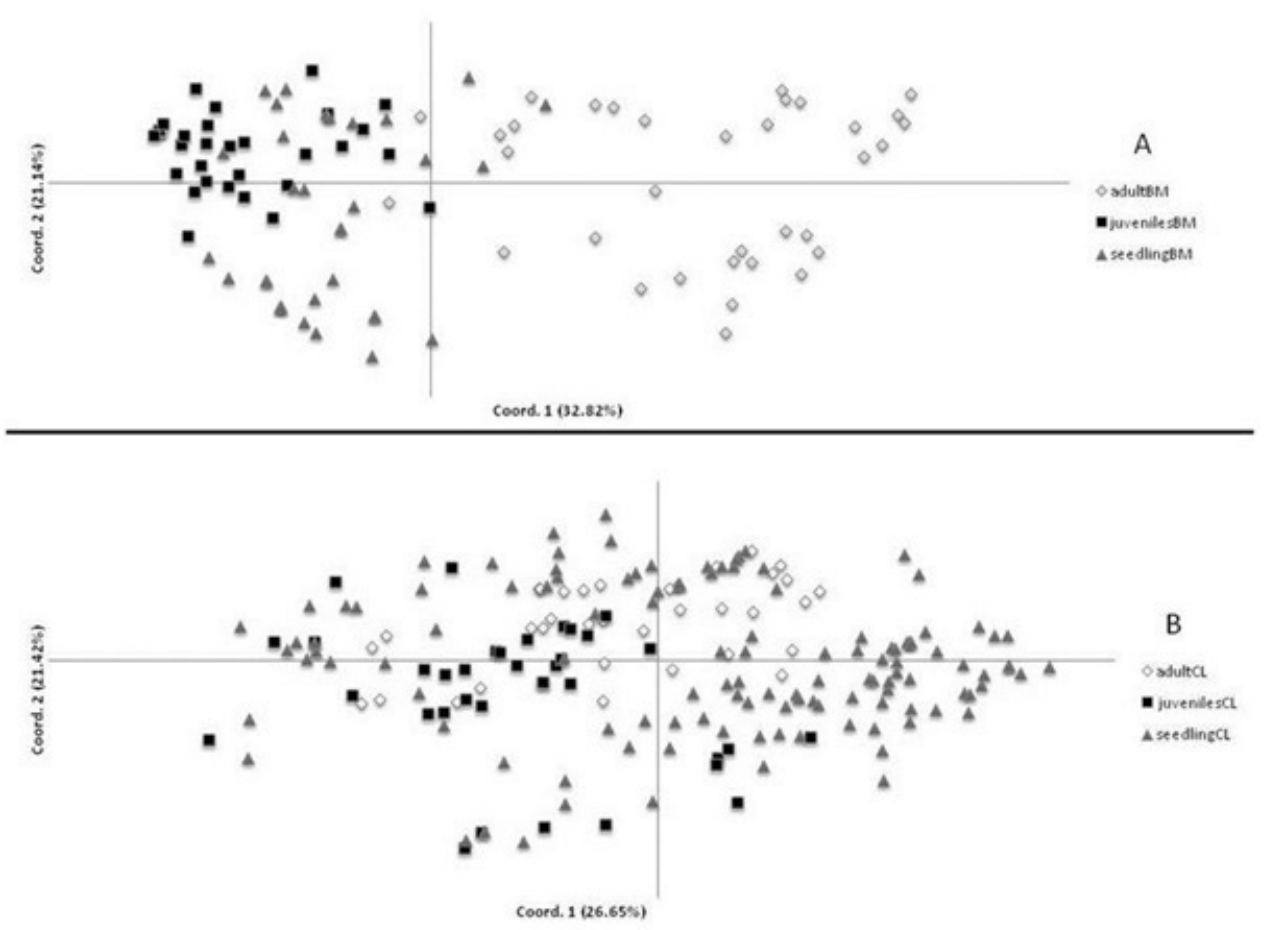

Figure 4. Distribution of three age classes (adult, juvenile, and seedling) in two-dimensional PCoA space for the two Hopea chinensis populations (A. BM, Ba Mun; B. CL, Cai Lim).

\section{DISCUSSION}

Population connectivity affects various ecological and evolutionary key features such as population growth rates, spatial distribution of genetic diversity, local adaptation, and global dynamics (Ronce, 2007). Because population connectivity shapes the resilience of populations against demographic, genetic, and environmental disturbance (Hanski, 1999), it also constitutes a key determinant of the populations' long-term viability. 
Knowledge of the geographical distribution of existing genetic variation has thus become an invaluable source of information, when aiming to delineate appropriate biological conservation units (Taylor and Dizon, 1996). A solid understanding of genetic population substructure and exchange between populations may complement demographic studies. Reaching this understanding has become a major goal of many ecological studies as it can inform both population ecologist and conservation managers. Our results showed moderate levels of genetic diversity within the BM and CL age classes, with a mean $H_{\mathrm{E}}$ of 0.371 and 0.425 for BM and CL, respectively. The $F_{\text {IS }}$ values were positive in all BM and CL age classes, showing a general lack of heterozygotes in all age classes. This suggests that some inbreeding is present. We also found the inbreeding level was significant for the adult and juvenile age classes of the BM population, as well as in the juvenile and seedling age classes of the CL population. Evidence for a recent bottleneck event was found in the seedling age class of the CL population. The juvenile CL age class also indicated a near significant bottleneck, suggesting that the number of adult individuals might have been reduced in the past.

Comparing the genetic structure of each age class in the BM and CL populations, both the Bayesian cluster analysis and the obtained $F_{\mathrm{ST}}$ values suggested that the genetic structure in the BM population could be divided into three groups. The $\Delta \mathrm{K}$ value was quite high (110.65) including adults, juveniles, and seedlings. In contrast, the genetic structure in the CL population could be divided into two groups that were more closely related between the age classes than in the BM population. A PCoA was used to examine the population structure in the collection distributed throughout the entire genome. The three age classes in the BM population revealed three clear groups and the first and second principal coordinates accounted for 32.82 and $21.14 \%$ of the variation, respectively. The three age classes in the CL population could be divided into two groups with the first and second principal coordinates accounting for 26.65 and $21.42 \%$, respectively. In the BM population, the first principal coordinate showed one group that was mostly composed of the adult age class and another group that included both the juvenile and seedling age classes together. However, the seedling age class was more spread along the first principal coordinate than the juvenile age class. The second principal coordinate divided the juvenile and the seedling age classes. The PCoA results showed that not all the adults in the BM population produced juveniles and seedlings, which explains why the genetic structure in the BM population could be separated into three difference clusters.

The focus of biodiversity conservation in tropical forests is often the protection of rare and endangered species. Consideration of population size is particularly important in tropical forests where the diversity of tree species is high, population densities are low, and many species are insect pollinated, which may limit pollen flow to relatively short distances (Dick et al., 2008). Natural forests in the humid tropics are commonly managed under selective logging regimes (Putz et al., 2012), applying minimum diameter cutting limits that may result in removing trees before they reach their optimal regeneration size. This can result in smaller reproductive populations that are at greater risk of inbreeding. Increased inbreeding and loss of genetic diversity can have severe negative effects on populations, for instance reduced growth, reproductive output, resistance to pests and diseases, and ability to adapt to environmental variation (Ellstrand and Elam, 1993; Hughes et al., 2008).

Maintaining the genetic viability of timber species is especially important for sustaining the productivity and quality of timber in tropical production forests. Conserving the genetic diversity of timber species also enhances the conservation value of the forests and contributes to landscape connectivity. The fact that tropical forests are often managed 
under selective logging regimes typically results in systematic removal of the largest and most fecund trees. Very little guidance is available to forest managers on the measures needed to maintain viable populations of timber species in the forests.

Although the genetic information provided in this study is still limited, enough knowledge may now exist to initiate the development of practical management guidelines on minimum population densities as a precondition for logging or documentation of sources of propagation material used in enrichment planting.

\section{Conservation priorities}

In conclusion, our results provide a better understanding of the genetic implications of the conservation of the threatened H. chinensis species in Vietnam. From a conservation point of view, effective management strategies should be formulated for both in situ and ex situ activities, considering the strong differentiation found among the three age classes in the BM population. This provides additional useful information for conservation, management, and restoration of populations to the Protection Forestry Department, Vietnam.

Our investigation only studied the spatial genetic structure, focusing on a limited number of generations. This may not be sufficient to reveal the complete picture of the genetic structure in populations with overlapping generations. Future studies should focus on revealing species characteristics that may indicate vulnerability to genetic erosion and the prevalence of these characteristics among species in mixed dipterocarp forest. This will help to identify species or species groups that may require specific measures to maintain genetically viable populations in logged forests and in the larger landscape. Such characteristics may include large size at reproductive maturity, slow increase in fecundity with size, fine-scale spatial genetic structure, low population densities, limited pollen dispersal, or high juvenile and seedling mortality.

\section{Conflicts of interest}

The authors declare no conflict of interest.

\section{ACKNOWLEDGMENTS}

Research supported by the Vietnam National Foundation for Science and Technology Development (NAFOSTED; grants \#106-NN.06-2013.08 and \#BAS42) (Basisfinanciering, Vrije Universiteit Brussels), and the NEF (Nagao Natural Environment Foundation).

\section{REFERENCES}

Appanah S and Chan HT (1981). Thrips: the pollinator of some dipterocarps. Malay. For. 44: 234-252.

Choo J, Juenger TE and Simpson BB (2012). Consequences of frugivore-mediated seed dispersal for the spatial and genetic structures of a neotropical palm. Mol. Ecol. 21: 1019-1031.http://dx.doi.org/10.1111/j.1365-294X.2011.05425.x

Dick CW, Hardy OJ, Jones FA and Petit RJ (2008). Spatial scales of pollen and seed-mediated gene flow in tropical rain forest trees. Trop. Plant Biol. 1: 20-33. http://dx.doi.org/10.1007/s12042-007-9006-6

Doyle JJ and Doyle JL (1987). A rapid DNA isolation procedure for small qualities of fresh leaf tissue. Phytochem. Bull. 19: 11-15. 
Earl DA and vonHoldt BM (2011). STRUCTURE HARVESTER: a website and program for visualizing STRUCTURE output and implementing the Evanno method. Conserv. Genet. Resour. 4: 359-361. http://dx.doi.org/10.1007/ $\underline{\text { s12686-011-9548-7 }}$

Ellstrand NC and Elam DR (1993). Population genetic consequences of small population size: implication for plant conservation. Annu. Rev. Ecol. Syst. 24: 217-242. http://dx.doi.org/10.1146/annurev.es.24.110193.001245

Evanno G, Regnaut S and Goudet J (2005). Detecting the number of clusters of individuals using the software STRUCTURE: a simulation study. Mol. Ecol. 14: 2611-2620. http://dx.doi.org/10.1111/j.1365-294X.2005.02553.x

Ezard THG and Travis JMJ (2006). The impact of habitat loss and fragmentation on genetic drift and fixation time. Oikos 114: 367-375. http://dx.doi.org/10.1111/j.2006.0030-1299.14778.x

Pl HR (2007). Hopea chinensis (Merrill) Handel-Mazzetti. Flora of China 13: 48-54.

Ge HM, Yang WH, Shen Y, Jiang N, et al. (2010). Immunosuppressive resveratrol aneuploids from Hopea chinensis. Chemistry 16: 6338-6345.http://dx.doi.org/10.1002/chem.201000230

Goudet J (1995). FSTAT (version 1.2): a computer program to calculate F-statistics. J. Hered. 86: 485-486.

Hamrick JL (2004). Response of forest trees to global environmental changes. For. Ecol. Manage. 197: 323-335. http:// dx.doi.org/10.1016/j.foreco.2004.05.023

Hanski I (1999). Habitat connectivity, habitat continuity, and metapopulations in dynamic landscapes. Oikos 87: 209-219. http://dx.doi.org/10.2307/3546736

Hughes AR, Inouye BD, Johnson MT, Underwood N, et al. (2008). Ecological consequences of genetic diversity. Ecol. Lett. 11: 609-623.http://dx.doi.org/10.1111/j.1461-0248.2008.01179.x

Iwata H, Konuma A and Tsumura Y (2000). Development of microsatellite markers in the tropical tree Neobalanocarpus heimii (Dipterocarpaceae). Mol. Ecol. 9: 1684-1685.http://dx.doi.org/10.1046/j.1365-294x.2000.01058-15.x

Kettle CJ, Hollingsworth PM, Jaffré T, Moran B, et al. (2007). Identifying the early genetic consequences of habitat degradation in a highly threatened tropical conifer, Araucaria nemorosa Laubenfels. Mol. Ecol. 16: 3581-3591. http://dx.doi.org/10.1111/j.1365-294X.2007.03419.x

Kramer AT, Ison JL, Ashley MV and Howe HF (2008). The paradox of forest fragmentation genetics. Conserv. Biol. 22: 878-885. http://dx.doi.org/10.1111/j.1523-1739.2008.00944.x

Lee SL, Wickneswari R, Mahani MC and Zakri AH (2000). Genetic diversity of a tropical species, Shorea leprosula Miq. (Dipterocarpaceae), in Malaysia: implications for conservation of genetic resources and tree improvement. Biotropica 32: 213-224. http://dx.doi.org/10.1111/j.1744-7429.2000.tb00464.x

Lee SL, Ng KKS, Lee CT, Norwati M, et al. (2004). Shorea lumutensis, an endangered dipterocarp with high levels of genetic diversity but low population differentiation. Conf. For. Forest Prod. Res. 166-173.

Lim LS, Wickneswari R, Lee SL and Latiff A (2001). Genetic structure of natural populations of Dryobalanops aromatica Gaertn. F. (Dipterocarpaceae) in Peninsular Malaysia using microsatellite DNA markers. In: In-situ and ex-situ conservation of commercial tropical trees (Thielges BA, Sastrapradja SD and Rimbawanto A, eds.). Gadja Mada University, Yogyekarta, 309-324.

Luikart G, Allendorf FW, Cornuet JM and Sherwin WB (1998). Distortion of allele frequency distributions provides a test for recent population bottlenecks. J. Hered. 89: 238-247. http://dx.doi.org/10.1093/jhered/89.3.238

Oleas NH, von Wettberg EJB and Negrón-Ortiz V (2014). Population genetics of the federally threatened Miccosukee gooseberry (Ribes echinellum), an endemic North American species. Conserv. Genet. 15: 749-755.

Ouborg NJ, Vergeer P and Mix C (2006). The rough edges of the conservation genetics paradigm for plants. J. Ecol. 94: 1233-1248. http://dx.doi.org/10.1111/j.1365-2745.2006.01167.x

Pandey M and Geburek T (2009). Successful cross-amplification of Shorea microsatellites reveals genetic variation in the tropical tree, Shorea robusta Gaertn. Hereditas 146: 29-32. http://dx.doi.org/10.1111/j.1601-5223.2009.02070.x

Peakall R and Smouse PE (2006). GENALEX 6.5: genetic analysis in Excel population genetic software for teaching and research. Mol. Ecol. Notes 6: 288-295. http://dx.doi.org/10.1111/j.1471-8286.2005.01155.x

Piry S, Luikart G and Cornuet JM (1999). BOTTLENECK: a computer program for detecting recent reductions in the effective population size using allele frequency data. J. Hered. 90: 502-503. http://dx.doi.org/10.1093/jhered/90.4.502

Pritchard JK, Stephens M and Donnelly P (2000). Inference of population structure using multilocus genotype data. Genetics 155: 945-959.

Putz FE, Zuidema PA, Synnott T, Peña-Claros M, et al. (2012). Sustaining conservation values in selectively logged tropical forest: the attained and the attainable. Conserv. Lett. 5: 296-303. http://dx.doi.org/10.1111/j.1755263X.2012.00242.X

Ronce O (2007). How does it feel to be like a rolling stone? Ten questions about dispersal evolution. Annu. Rev. Ecol. Evol. Syst. 38: 231-253. http://dx.doi.org/10.1146/annurev.ecolsys.38.091206.095611

Takeuchi Y, Ichikawa S, Konuma A, Tomaru N, et al. (2004). Comparison of the fine-scale genetic structure of three dipterocarp species. Heredity 92: 323-328. http://dx.doi.org/10.1038/sj.hdy.6800411 
Taylor BL and Dizon AE (1996). The need to estimate power to link genetics and demography for conservation. Conserv. Biol. 10: 661-664. http://dx.doi.org/10.1046/j.1523-1739.1996.10020661.x

Ujino T, Kawahara T, Tsumura Y, Nagamitsu T, et al. (1998). Development and polymorphism of simple sequence repeat DNA markers for Shorea curtisii and other Dipterocarpaceae species. Heredity (Edinb) 81: 422-428. http://dx.doi. org/10.1046/j.1365-2540.1998.00423.x

Van Oosterhout C, Hutchinson WF, Wills DPM and Shipley P (2004). MICRO-CHECKER: software for identifying and correcting genotyping errors in microsatellite data. Mol. Ecol. Notes 4: 535-538. http://dx.doi.org/10.1111/j.1471$\underline{8286.2004 .00684 . \mathrm{X}}$

Vietnam red data book, part II. Plants. (2007). Ministry of Science and Technology and Vietnamese Academy of Science and Technology, 550.

Weir BS and Cockerham CC (1984). Estimating F-statistics for the analysis of population structure. Evolution 38: 13581370. http://dx.doi.org/10.2307/2408641

Yan T, Wang T, Wei W, Jiang N, et al. (2012). Polyphenolic acetylcholinesterase inhibitors from Hopea chinensis. Planta Med. 78: 1015-1019. http://dx.doi.org/10.1055/s-0031-1298623 